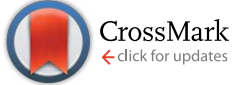

Cite this: RSC Adv., 2017, 7, 3021

\title{
The concise synthesis and biological evaluation of $C$-glycosyl chalcone analogues inspired by the natural product aspalathin $\dagger$
}

\author{
Tao Zhang and Zhijie Fang* \\ We describe the synthesis and biological evaluation of C-glycosyl chalcone analogues of aspalathin. The \\ $\mathrm{DPPH}$ radical scavenging method was used to detect their antioxidant activity and an MTT colorimetric \\ assay was employed to test the anticancer activity against Hep-G2 liver carcinoma cells and MCF-7 \\ human breast carcinoma cells. The antioxidant ability between $C$-furanosides and $C$-pyranosides was \\ compared. Compound $3 \mathrm{c}^{\prime}$ was shown to be the most promising compound with good antioxidant ability \\ and the ability to inhibit Hep-G2 and MCF-7 cells, with $I_{50}$ values of $4.9 \mu M$ and $19 \mu \mathrm{M}$, respectively.
}

Received 18th November 2016 Accepted 14th December 2016

DOI: 10.1039/c6ra26969a

www.rsc.org/advances according to the statement mentioned above, the synthesis of its analogues is significant and meaningful.

Recently, we have systematically explored the one-step synthesis of compound $\mathbf{1}$ from glucose catalyzed by different Lewis acids. ${ }^{19}$ The target product $C$-glycoside-derived tetrahydrofurans comprised of a sugar ring and a rigid furan ring with an acetyl group, which can be used as a reactive part to prepare derivatives of $C$-glycosyl chalcones. Herein, inspired by the structure of aspalathin and the recent studies, we report a concise synthesis of aspalathin analogues, with glucose as a starting material in only three steps.

\section{Experimental}

\subsection{General experimental procedures}

All chemicals were of analytical grade and used without further purification. Cells were supplied by Guang Liang group in Wenzhou Medical University. Reactions were monitored using thin-layer chromatography on silica gel coated TLC plates and detection was performed by UV absorption $(254 \mathrm{~nm})$ where applicable and by spraying with $50 \%$ sulfuric acid in ethanol, followed by charring at $150{ }^{\circ} \mathrm{C}$. Melting points (m.p.) were determined on a WRS-1B digital melting-point apparatus (Shanghai Shenguang Instrument Co., Ltd). ${ }^{1} \mathrm{H}$ and ${ }^{13} \mathrm{C}$ NMR spectra were recorded on Bruker-500 (500/125 MHz) and Bruker$300(300 / 75 \mathrm{MHz})$ spectrometers. ESI-LCMS spectra were obtained on a Shimadzu LCMS-2010 EV mass spectrometer. Elemental analysis was carried out on a Perkin Elmer 2400 II.

\subsection{Cytotoxicity assay}

An MTT (3-(4,5-dimethylthiazol-2-yl)-2,5-diphenyl-2 $H$-tetrazolium bromide) assay was performed. Cells were seeded in a 96well plate at a concentration of $1.0 \times 10^{-4}$ cells per well and allowed to adhere overnight. Five replicates were prepared for
Department of Chemical Engineering, Nanjing University of Science \& Technology, Nanjing 210094, P. R. China. E-mail: zjfang@njust.edu.cn

$\dagger$ Electronic supplementary information (ESI) available. See DOI: 10.1039/c6ra26969a 
each treatment and cultured for 48 or $72 \mathrm{~h}$. After $20 \mu \mathrm{L}$ of MTT $\left(5 \mathrm{mg} \mathrm{mL}^{-1}\right)$ was added to each well, the cells were cultured for another $4 \mathrm{~h}$. The supernatant was discarded. After $150 \mu \mathrm{L}$ of DMSO was added to each well, the samples were incubated for $30 \mathrm{~min}$ and then swirled for $10 \mathrm{~min}$. The absorbance $(A)$ at $570 \mathrm{~nm}$ was measured using a microplate reader. Experiments were repeated three times and averaged.

\subsection{Determination of the antioxidant activity using the DPPH radical scavenging method}

The antioxidant activity of the $C$-glycoside derivatives was measured in terms of their hydrogen donating or radical scavenging ability using the stable radical, DPPH. An $80 \%$ aqueous ethanolic solution $(0.6 \mathrm{~mL})$ of the antioxidant was placed in a cuvette and $1.8 \mathrm{~mL}$ of a $6 \times 10^{-5} \mathrm{M}$ aqueous ethanolic solution of DPPH (at $0.25 \mathrm{~mol}$ of antioxidant per mol of DPPH) was added. Absorbance measurements commenced immediately. The decrease in absorbance at $517 \mathrm{~nm}$ was determined continuously with data captured at $5 \mathrm{~s}$ intervals with a Beckman DU-65 spectrophotometer and Data Capture software for $2 \mathrm{~h}$. An $80 \%$ aqueous ethanol solution was used to zero the spectrophotometer. The absorbance of the DPPH radical without antioxidant, i.e. the control, was measured daily. All determinations were performed in duplicate. The percentage inhibition of the DPPH radical by the samples was calculated according to the following formula:

$$
\% \text { inhibitor }=\left[\left(A_{(0)}-A_{(t)}\right) / A_{(0)}\right] \times 100
$$

where $A_{(0)}$ is the absorbance of the control at $t=0 \mathrm{~min}$ and $A_{(t)}$ is the absorbance of the antioxidant at $120 \mathrm{~min}$.

\subsection{Synthesis of the $C$-glycosyl flavonoid analogues}

2.4.1 General synthesis of compounds $2 \mathrm{a}-2 \mathrm{c}$. To a solution of 3-acetyl-5- $C$-(2,3-dihydroxy-1,4-anhydro- $\beta$-D-erythro-tetrofuranosyl)2-methylfuran $1(0.226 \mathrm{~g}, 1.0 \mathrm{mmol})$ and aromatic aldehydes (1.5 $\mathrm{mmol})$ in ethanol $(4 \mathrm{~mL})$ was added $\mathrm{NaOH}(20 \%, 0.15 \mathrm{~mL})$ at room temperature. The reaction mixture was placed in a preheated oil bath and stirred at $60{ }^{\circ} \mathrm{C}$ for $6 \mathrm{~h}$. After completion of the reaction as indicated by TLC $(1: 2$ petroleum ether-ethyl acetate), the reaction mixture was evaporated to dryness under reduced pressure, dissolved in dichloromethane and washed with brine. The organic phase was collected and dried over anhydrous $\mathrm{Na}_{2} \mathrm{SO}_{4}$. The solvent was evaporated under reduced pressure and the residue was further purified by silica gel column chromatography using 2:1 petroleum ether-ethyl acetate to furnish pure products.

2.4.2 General synthesis of compounds $3 \mathbf{a}^{\prime}-3 \mathbf{c}^{\prime}$. A suspension of compound $2 \mathrm{a}(0.21 \mathrm{~g}, 0.5 \mathrm{mmol})$ and $10 \% \mathrm{Pd} / \mathrm{C}(50 \mathrm{mg})$ in dichloromethane $(5 \mathrm{~mL})-\mathrm{MeOH}(10 \mathrm{~mL})$ was stirred under $\mathrm{H}_{2}$ at atmospheric pressure for $4 \mathrm{~h}$. The reaction mixture was filtered, concentrated under a vacuum, and purified by silica gel column chromatography using 1:2 petroleum ether-ethyl acetate to furnish pure products.

2.4.3 General synthesis of compounds $5 \mathrm{a}$ and $5 \mathrm{~b}$. To a solution of 1-C-( $\beta$-D-glucopyranosyl)-propan-2-one $(5.0 \mathrm{~g}, 23.0$ $\mathrm{mmol})$ and aromatic aldehydes $(3.42 \mathrm{~g} 28.0 \mathrm{mmol})$ in ethanol (4.5 $\mathrm{mL})$ was added TEA $(0.11 \mathrm{~mL}, 0.77 \mathrm{mmol})$ and proline $(0.4 \mathrm{~g} 3.45$ $\mathrm{mmol}$ ) at room temperature. The reaction mixture was stirred at r.t. for $48 \mathrm{~h}$. After completion of the reaction as indicated by TLC (1:2 petroleum ether-ethyl acetate), the product was precipitated in the solvent. Then, the product was filtered and washed with cold water. The pure product was then obtained.

2.4.4 Synthesis of compound 5c. To a solution of compound 4c $(5.0 \mathrm{~g}, 23.0 \mathrm{mmol})$ and 3,4-dihydroxybenzaldehyde $(3.87 \mathrm{~g} 28.0 \mathrm{mmol})$ in ethanol $(4.5 \mathrm{~mL})$ was added TEA $(0.11 \mathrm{~mL}, 0.77 \mathrm{mmol})$ and proline $(0.4 \mathrm{~g} 3.45 \mathrm{mmol})$ at room temperature. The reaction mixture was stirred at r.t. for $48 \mathrm{~h}$. After completion of the reaction as indicated by TLC (1:2 petroleum ether-ethyl acetate), the product was precipitated in the solvent. Then, the product was filtered and washed with cold water. The pure product was then obtained $(6.15 \mathrm{~g})$ in 92.3\% yield as a light yellow powder.

2.4.5 Synthesis of compound 6. A solution of compound $5 \mathrm{c}$ $(0.5 \mathrm{~g}, 0.98 \mathrm{mmol})$ and $\mathrm{MeONa}(0.1 \mathrm{~g} 1.56 \mathrm{mmol})$ in methanol $(10 \mathrm{~mL})$ was stirred at room temperature for $2 \mathrm{~h}$. After completion of the reaction, the mixture was treated with cation exchange resin (sodium form) to reach $\mathrm{pH}$ 5. The resin was filtered and methanol was evaporated. The final product was obtained $(0.25 \mathrm{~g})$ in $75.1 \%$ yield as a yellow oil.

\section{Results and discussion}

\subsection{Design}

Structurally, aspalathin is comprised of a glycosyl unit and a dihydrochalcone moiety connecting through a $\beta$-glycosidic bond (Fig. 1). Usually, Friedel-Crafts and Koenigs-Knorr glycosylation methods are used in the synthesis of aspalathin. However, due to the high steric hindrance of the substrate, the product yields are relatively low. ${ }^{17}$ Therefore, we designed and synthesized three types of chalcone analogues comprised of a glycosyl unit and dihydrochalcone-like moiety via aldol reaction. In addition, the $C$-pyranoside chalcones were also synthesized in order to compare their antioxidant activity with $C$-furanosides. Both the series of compounds have a carbohydrate part and chalcone-like part, which are similar with aspalathin to some extent. The method avoids using the FriedelCrafts and Koenigs-Knorr glycosylation methods and is much more efficient and economic.

\subsection{Synthesis}

We have reported that the condensation of glucose with acetylacetone in the presence of a Lewis acid in ethanol afforded
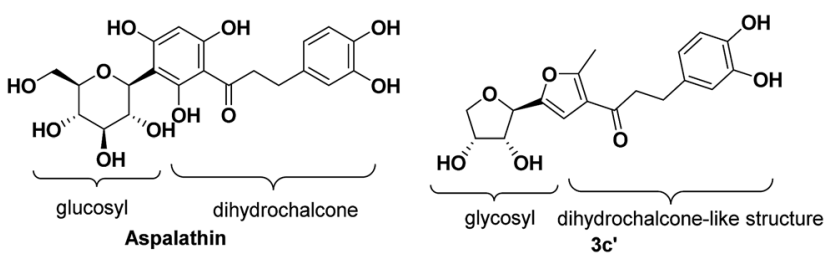

Fig. 1 The structure of aspalathin and compound $3 c^{\prime}$. 
compound $1 .^{19}$ To synthesize compounds $3 \mathbf{a}^{\prime}-\mathbf{3} \mathbf{c}^{\prime}$, first, compound 1 in ethanol was refluxed with aromatic aldehydes using a base-catalyst in order to afford $(E)-\alpha, \beta$-unsaturated ketones i.e. 2a-2c. Then, compounds $\mathbf{2 a - 2 c}$ were subjected to hydrogenolysis in the presence of a catalyst, $10 \%$ palladiumcarbon, under a hydrogen atmosphere in a dichloromethane and ethanol mixture to afford the desired compounds $\mathbf{3} \mathbf{a}^{\prime}-\mathbf{3} \mathbf{c}^{\prime}$ (Scheme 1). The total yield of the three steps was around 44$52 \%$. When compared with the synthetic route of aspalathin, the method for the synthesis of compounds $3 \mathbf{a}^{\prime}-\mathbf{3} \mathbf{c}^{\prime}$ was simpler and the reaction materials were of low cost.

Compounds $\mathbf{5 a}$ and $\mathbf{5 b}$ can be synthesized via a direct aldol condensation, ${ }^{20}$ which was catalyzed by proline-TEA in the presence of methanol in yields of 95\% and 93\%, respectively. Due to the high activity and excellent water solubility of compound 6, it is not easy to separate the final product after the one-step direct aldol reaction. Herein, we prepared it via two steps (Scheme 2), compound $\mathbf{4 b}$ was selected as the starting material, which lowers the polarity of the intermediate and was helpful for the separation of the final product. In addition, in the ${ }^{1} \mathrm{H}$ NMR spectra of all the synthesized chalcones, the hydrogens on the $\mathrm{C}=\mathrm{C}$ bond have larger coupling constants (furanoside, $J=15.6 \mathrm{~Hz}$; pyranoside, $J=16 \mathrm{~Hz}$ ), which indicate that the configurations of all synthesized chalcones are the $E$ isomer.

\subsection{Bioassay}

Naturally occurring $C$-aryl glycosides exhibit a range of interesting biological properties. Aspalathin shows potent antioxidant

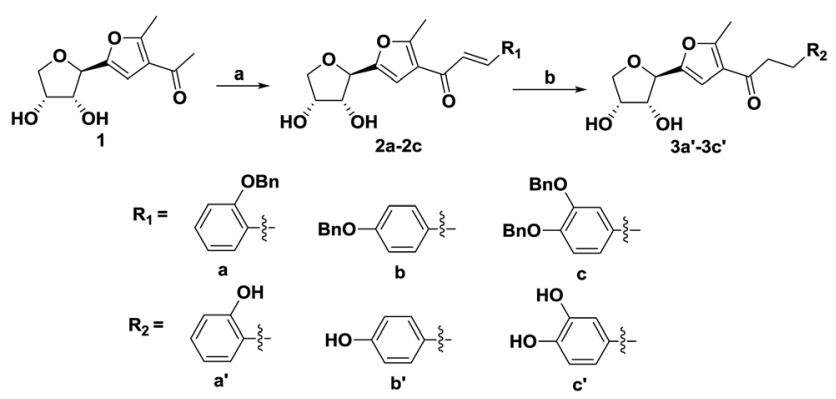

Scheme 1 Preparation of the $\mathrm{C}$-furanoside chalcone analogues Reagents and conditions: (a) $20 \% \mathrm{NaOH}$, aromatic aldehyde, $60{ }^{\circ} \mathrm{C}$, 6 h; (b) $10 \% \mathrm{Pd} / \mathrm{C}, \mathrm{H}_{2}$, dichloromethane/methanol (1 : 1), r.t., 4 h.

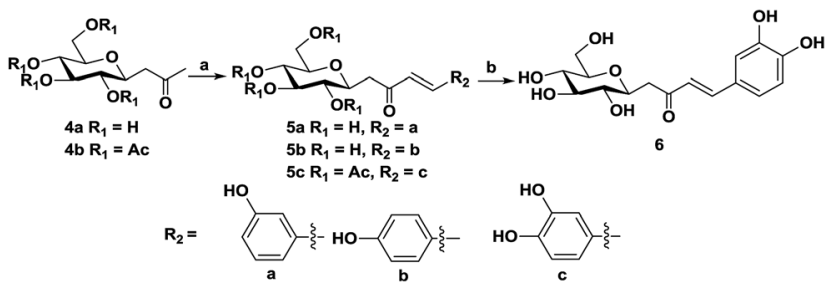

Scheme 2 Preparation of the C-pyranoside chalcone analogues. Reagents and conditions: (a) TEA-proline, aromatic aldehyde, r.t., $48 \mathrm{~h}$; (b) MeONa, methanol. and radical scavenging activity, and has recently been found to inhibit the proliferation and infiltration of liver cancer cells. ${ }^{13}$ Therefore, to further explore the bioactivity of the $C$-glycosyl chalcone analogues, we studied their antioxidant activity using the DPPH radical scavenging method and their anticancer activity using the MTT experiments.

We synthesized polyphenol compounds based on $C$-glycosides as mentioned above to compare the antioxidant ability. The polyphenols binding with different sugars showed different DPPH radical scavenging ability as seen in Fig. 2, the decrease in absorbance of the DPPH radical ( $\mathrm{DPPH}^{\circ}$ ) due to its reduction by different antioxidants was illustrated. The absorbance decreases as a result of a color change from purple to yellow as the radical was scavenged by the antioxidants through donation of hydrogen to form the stable DPPH-H. The more rapidly the absorbance decreases, the more potent the antioxidant activity of the compound is in terms of its hydrogen donating ability.

Compounds $\mathbf{3} \mathbf{a}^{\prime}, \mathbf{3} \mathbf{b}^{\prime}, \mathbf{5} \mathbf{a}, \mathbf{5} \mathbf{b}$ and $\alpha$-arbutin showed a slow decrease in absorbance, whereas the other compounds, including ascorbic acid, rutin, compound $\mathbf{3} \mathbf{c}^{\prime}$ and $\mathbf{6}$, displayed a rapid decrease in the absorbance when the analysis was performed at $0.25 \mathrm{~mol} \mathrm{~mol}^{-1} \mathrm{DPPH}$ radical. The percentage inhibition of the DPPH radical by the compounds tested is given in Table 1. Joubert's study ${ }^{\mathbf{1 1}}$ showed that the antioxidant ability of aspalathin was slightly more than rutin; therefore, the antioxidant activity of these compounds, as determined by the DPPH radical scavenging method, decreased in the order ascorbic acid $>$ aspalathin $>$ rutin $>3 \mathbf{c}^{\prime}>\alpha$-arbutin $>\mathbf{5 b}>\mathbf{5 a}>\mathbf{3} \mathbf{b}^{\prime}>\mathbf{3} \mathbf{a}^{\prime}$. Even though rutin is more potent than $3 \mathbf{c}^{\prime}$ as an antioxidant, the

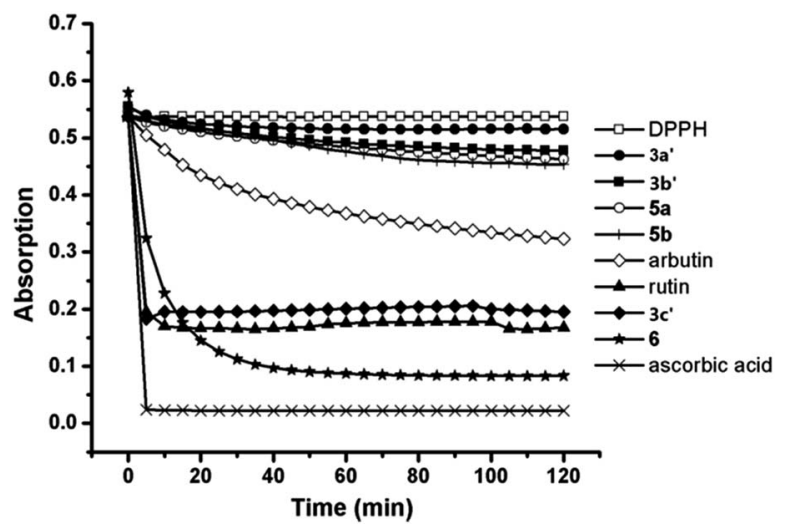

Fig. 2 The free radical scavenging effect of the pure C-glycosyl chalcone derivatives using the DPPH method $\left(0.25 \mathrm{~mol} \mathrm{~mol}^{-1}\right)$. $\alpha$-Arbutin, ascorbic acid and rutin were used as reference materials.

Table 1 The percentage inhibition of the DPPH radical

\begin{tabular}{llll}
\hline Compound & \% inhibition & Compound & \% inhibition \\
\hline -Arbutin & 39.93 & $\mathbf{3 a}^{\prime}$ & 9.76 \\
Ascorbic acid & 95.91 & $\mathbf{3 b}^{\prime}$ & 13.3 \\
Rutin & 68.85 & $\mathbf{3 c}^{\prime}$ & 63.55 \\
$\mathbf{5 a}$ & 13.89 & $\mathbf{6}$ & 85.60 \\
$\mathbf{5 b}$ & 15.66 & &
\end{tabular}



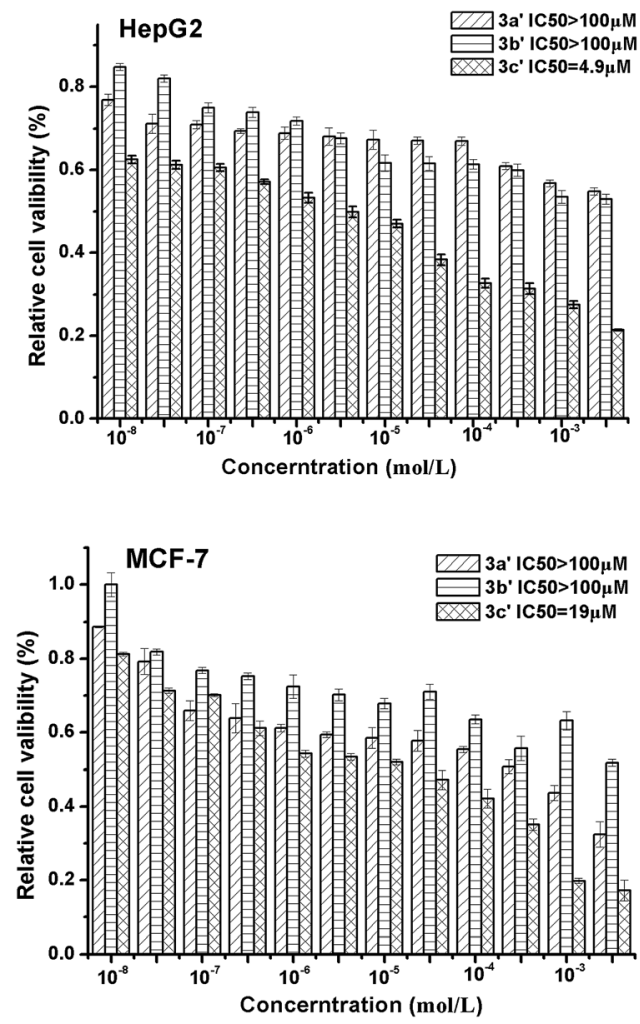

Fig. 3 MTT assay of compounds $3 a^{\prime}, 3 b^{\prime}$ and $3 c^{\prime}$.

value gap was not significant. Compound $3 \mathbf{c}$ was found to be a potent DPPH radical scavenger with $63.55 \%$ inhibition in terms of these results. In addition, as seen in Table 1, the antioxidant ability of $C$-pyranosides was higher than that of the $C$-furanosides in this test.

As $C$-glycosyl flavonoids have been recently found to inhibit the proliferation and infiltration of liver cancer cells, Fig. 3 shows the anti-cancer activity of compounds $\mathbf{3} \mathbf{a}^{\prime}, \mathbf{3} \mathbf{b}^{\prime}$ and $\mathbf{3} \mathbf{c}^{\prime}$ with two types of cancer cells (i.e. liver cancer cells HepG2 and breast cancer cells MCF-7). Compound 3 $\mathbf{c}^{\prime}$ exhibited significant inhibition against HepG2 and MCF-7 cells and the $\mathrm{IC}_{50}$ values can reach $4.9 \mu \mathrm{M}$ and $19 \mu \mathrm{M}$, respectively.

\section{Conclusion}

In summary, we have demonstrated the synthesis of aspalathin analogues and their bioactivities. DPPH radical scavenging experiments showed the antioxidant ability of compound $\mathbf{3 \mathbf { c } ^ { \prime }}$ was basically the same as rutin and the antioxidant ability of the $C$ pyranosides was higher than the $C$-furanosides. The MTT colorimetric assay indicated that compound $3 \mathbf{c}^{\prime}$ can also inhibit the proliferation of HepG2 cells and MCF-7 cells with $\mathrm{IC}_{50}$ values of 4.9 $\mu \mathrm{M}$ and $19 \mu \mathrm{M}$, respectively. The analogues of $C$-glycosyl chalcone aspalathin are easy to synthesize and deserve further study.

\section{Acknowledgements}

The authors appreciate the financial support from the prospective joint project of Production, Education \& Research in Jiangsu Province, China (Grant No. BY2013004-02).

\section{References}

1 R. Schoeneborn and R. Mues, Phytochemistry, 1993, 34, 11431145.

2 S. J. Semple, S. F. Nobbs, S. M. Pyke, G. D. Reynolds and R. L. P. Flower, J. Ethnopharmacol., 1999, 68, 283-288.

3 L. Hu, L. Li, D. Xu, X. Xia, R. Pi, D. Xu, W. Wang, H. Du, E. Song and Y. Song, Chem.-Biol. Interact., 2014, 213, 51-59.

4 B. A. Bhat, K. L. Dhar, S. C. Puri, A. K. Saxena, M. Shanmugavel and G. N. Qazi, Bioorg. Med. Chem. Lett., 2005, 15, 3177-3180.

5 P. W. Snijman, S. Swanevelder, E. Joubert, I. R. Green and W. Gelderblom, Mutat. Res., 2007, 631, 111-123.

6 L. Standley, P. Winterton, J. L. Marnewick, W. C. Gelderblom, E. Joubert and T. J. Britz, J. Agric. Food Chem., 2001, 49, 114-117.

7 J. W. Drynan, M. N. Clifford, J. Obuchowicz and N. Kuhnert, Nat. Prod. Rep., 2010, 27, 417-462.

8 B. H. Koeppen and D. G. Roux, Biochem. J., 1966, 99, 604-609. 9 E. Joubert, T. Beelders, D. Beer, C. J. Malherbe and A. J. Villiers, J. Agric. Food Chem., 2012, 60, 9171-9179.

10 J. D. Merwe, E. Joubert, M. Manley, D. Beer, C. J. Malherbe and W. C. A. Gelderblom, J. Agric. Food Chem., 2010, 58, 2214-2220.

11 A. Gadow, E. Joubert and C. F. Hansmann, J. Agric. Food Chem., 1997, 45, 632-638.

12 M. J. Son, M. Minakawa, Y. Miura and K. Yagasaki, Eur. J. Nutr., 2013, 52, 1607-1619.

13 S. Kwak, M. S. Han and J. S. Bae, Fitoterapia, 2015, 100, 179186.

14 Y. Kazumi, M. Yutaka, H. Shuichi and N. Hiromichi, JP Patent, \#2007197409, August 09, 2007.

15 E. Joubert, P. Winterton, T. J. Britz and W. C. A. Gelderblom, J. Agric. Food Chem., 2005, 53, 10260-10267.

16 M. Pengilly, E. Joubert, W. H. Zyl, A. Botha and M. Bloom, J. Agric. Food Chem., 2008, 56, 4047-4053.

17 A. Yepremyan, B. Salehani and T. G. Minehan, Org. Lett., 2010, 12, 1580-1583.

18 Z. Han, M. C. Achilonu, P. S. Kendrekar, E. Joubert, D. Ferreira, S. L. Bonnet and J. H. Westhuizen, J. Nat. Prod., 2014, 77, 583-588.

19 Y. F. Xiang, Z. J. Fang and L. X. Li, Chem. Res. Appl., 2013, 25, 1426-1429.

20 J. F. Wang, M. Lei, Q. Li, Z. Ge, X. Wang and R. Li, Tetrahedron, 2009, 65, 4826-4833. 